\title{
Finalizando 2017
}

Nas primeiras palavras deste número 68 da Revista do Instituto de Estudos Brasileiros - que encerra o ano e ganha novos editores, segundo o princípio de rodízio que norteia nossa publicação - temos a comemorar uma boa notícia. Por iniciativa dos editores que nos antecederam, a publicação se inscreveu no edital do Programa de Apoio às Publicações Científicas Periódicas da USP, vinculado ao Sistema Integrado de Bibliotecas (SIBi/USP), e foi selecionada para receber a dotação de uma verba significativa, que permitirá realizar a impressão de boa parte dos números recentes. Não há dúvida de que esse resultado confirma a qualidade e excelência com que o trabalho tem sido feito. No entanto, alguém pode perguntar: que sentido tem em nossos dias imprimir uma revista que já está disponível on-line? A resposta para essa questão demandaria um espaço maior, mas pode ser resumida ao argumento central: ainda que a disponibilidade virtual dessas publicações alcance maior número de leitores e envolva custos menores, nem por isso cobre todas as situações de usufruto e de troca intelectual. Na verdade, são muitos os meios de conhecimento disponíveis, e eles não se excluem mutuamente. Situação semelhante vem acontecendo com o mundo editorial. Já se sabe atualmente que o "livro eletrônico" está longe de eliminar a edição em papel, que, ao contrário das previsões catastróficas que se fizeram no século passado, tende a resistir junto aos leitores. A previsão atual é que os dois mercados de livros correrão em paralelo, ainda que em proporções distintas.

$E$ com as revistas acadêmicas não é diferente. Os exemplares impressos - em tiragens baixas, de 200 a 300 exemplares - podem (e devem) ser usados com o intuito de uma difusão seletiva e focada, alternativa ao modelo da internet. É o caso, por exemplo, do intercâmbio de publicações entre universidades nacionais e internacionais, que ainda permanece; ou ainda a divulgação à imprensa e a órgãos culturais do país, bem como o envio para intelectuais potencialmente interessados nos assuntos abordados. Isso quer dizer que a versão impressa da revista cumpre principalmente uma função ativa de intervenção acadêmica, em paralelo à dimensão generalizada permitida pela web. E a convivência acadêmica somente se amplia ao contar com uma variedade de meios de acesso.

Passemos agora à apresentação dos artigos deste número. Desta vez, não apresentamos dossiê temático, como ocorre habitualmente, para dar espaço e privilegiar a interdisciplinaridade e diversidade de ensaios - sempre com contribuições importantes para cada campo 
de estudo. De início, privilegiamos o tema racial, que vem ganhando proeminência nos debates sociais, com a presença de dois ensaios.

"Cultura e revanche na guerra social: comentários sobre Branco sai, preto fica, de Adirley Queirós" se dedica a analisar o filme Branco sai, preto fica, que tem o mérito de compor um híbrido de documentário e ficção em torno de um baile de dança black. Segundo os autores do texto - Taiguara Belo de Oliveira e Danielle Edite Ferreira Maciel, ambos da Universidade de São Paulo -, o longa-metragem se destaca pela ousadia estética e soluções encontradas, mas sem de fato apresentar uma alternativa política viável.

Em seguida, Alessandra Ribeiro Martins e Wilson Ribeiro dos Santos Junior (da Pontifícia Universidade Católica de Campinas - PUC-Campinas) apresentam uma reflexão sobre a reterritorialização da matriz africana nos territórios urbanos da cidade de Campinas, a partir do levantamento de monumentos, praças e ruas que receberam nomes de personagens negros. $\mathrm{O}$ artigo intitulado "O Projeto Ruas de Histórias Negras e a representação da matriz africana em Campinas: a disputa do território urbano - um estudo de caso" traz um debate importante sobre o processo de apagamento da tradição colonial da região, que contou com significativa população escrava.

Na sequência, apresenta-se “O ‘Tantum ergo virado acalanto’: o vigor da brasilidade”, um ensaio sobre o "mulato" Mário de Andrade, mais especificamente sobre a trajetória de descoberta do escritor em torno da importância do acalanto no universo da cultura oral. A partir de um lembrete de Mário, a pesquisadora da USP Silvia De Ambrosis Pinheiro Machado disseca a importância do tema no livro O Turista Aprendiz.

Em continuidade ao tema racial, o artigo seguinte - "Indigenização de práticas de numeramento no desenvolvimento e na gestão de projetos sociais do povo indígena Xakriabá" - trata do desenvolvimento e gestão de projetos sociais junto ao povo indígena Xakriabá, nas margens do Rio São Francisco. Nesse contexto, destaca-se a questão da "indigenização da modernidade", analisada pelas autoras Augusta Aparecida Neves de Mendonça (Fundação Mineira de Educação e Cultura - Fumec-MG) e Maria da Conceição Ferreira Reis Fonseca (Universidade Federal de Minas Gerais - UFMG), atentas ao modo como os povos indígenas "vêm elaborando culturalmente tudo aquilo que lhes foi infligido".

Após essa sequência inicial de artigos sobre tópicos raciais e brasileiros, abrimos espaço para duas contribuições francesas. Em "Correspondances et journaux de femmes: une fonction mémorielle?”, Françoise Simonet-Tenant, da Universidade de Rouen-Normandie, reflete sobre a importância das cartas e dos diários íntimos como fontes fundamentais para uma compreensão da produção literária, filosófica de autoras mulheres, algumas das quais pouco reconhecidas pela história. Em especial, o artigo se detém sobre a escrita íntima de três mulheres escritoras - Juliette Drouet, Catherine Pozzi e Simone de Beauvoir-, parceiras de três escritores importantes. E apresenta de modo inovador o tema das parcerias afetivas e intelectuais, bem como o lugar relegado às mulheres. Em seguida, temos um texto de Clara Lévy, professora da Universidade de Paris VIII, que discorre sobre "Patrick Modiano, à l'articulation entre champ de diffusion restreinte et champ de grande production”. Nele, a autora contextualiza a posição de Modiano no campo das letras francesas e também se detém na visibilidade e comercialização do autor, por ocasião do recebimento do Prêmio Nobel, em 20I4. A partir de um estudo de caso a autora desenvolve uma reflexão teórico-metodológica original acerca da necessidade de 
revisar as oposições estabelecidas por Pierre Bourdieu entre dimensão restrita e dimensão ampliada da circulação dos bens culturais.

Na sequência, voltamos aos temas brasileiros, e ganha destaque a produção artística de Tom Zé, especialmente aquela produzida em torno ao projeto que designou como "música operária", envolvendo uma produção musical a partir de ferramentas, máquinas de oficina, fitas magnéticas etc. Em "A produção artística de Tom Zé na década de I970: considerações sobre o projeto da música 'operária' e o disco Estudando o samba", o estudioso da Universidade Estadual de Campinas (Unicamp) Guilherme Araujo Freire analisa o disco Estudando o samba, em que o músico baiano leva a experimentação sonora ao limite. $\mathrm{O}$ artigo seguinte se volta para o poeta João Cabral de Melo Neto, em ensaio de Fábio José dos Santos de Oliveira, da Universidade Federal do Maranhão (UFMA). Em "A lâmina que opera: um estudo sobre João Cabral e Marianne Moore", o autor se detém sobretudo nos poemas que João Cabral escreveu sobre a poeta norte-americana Marianne Moore, muito admirada pelo pernambucano. Nos versos sobre ela, percebe-se muito da autoconsciência desenvolvida por Cabral no sentido de valorizar uma poética em que predomina a objetividade e a precisão.

O ensaio posterior, "Candian: o último caipira”, volta-se, como o nome indica, para uma tematização contemporânea sobre a cultura caipira. A partir da documentação deixada por Ernani Silva Bruno, disponível no IEB, e inspirados nas ideias de Antonio Candido sobre o tema, os estudiosos Vitor Sartori Cordova e Jane Victal (Pontifícia Universidade Católica de Campinas - PUC-Campinas) se voltam para um estudo de caso: o cotidiano do sr. Candian, líder da cidade paulista de Iracemápolis e vinculado às práticas tradicionais do campo. $O$ erotismo literário comparece na sequência, foco do ensaio intitulado “A poesia erótica de Lucas José d'Alvarenga”, em que Gracinéa I. Oliveira (Faculdade de Ciências Sociais Aplicadas de Belo Horizonte - FACISABH) analisa obra desse autor cujos versos foram vistos como ousados para a época. Trata-se de uma produção em que a escrita reitera imagens por meio de antíteses e metáforas, criando certo espírito de leveza ao tratar do sexo. Por fim, passamos ao modernismo brasileiro, em artigo de José Luís Jobim (Universidade Federal Fluminense - UFF), intitulado "Francesismo ou nacionalismo? Dilemas do modernismo brasileiro nas cartas dos anos I920". A partir das correspondências de Carlos Drummond de Andrade, Mário de Andrade e Manuel Bandeira o autor reflete sobre as referências francesas e europeias presentes na produção e reflexão de tais autores. Ao mesmo tempo, aponta o dilema subjacente à troca de ideias nos anos I920: adotar o francesismo ou o nacionalismo?

Na seção de resenhas deste número, foram selecionados lançamentos relevantes, que merecem registro pelas questões levantadas. Primeiramente, Ieda Lebensztayn se debruça sobre o livro Graciliano Ramos e a Cultura Política: mediação editorial e construção do sentido, no qual Thiago Mio Salla rastreia a colaboração do escritor alagoano para uma importante publicação dos anos I940. Em seguida, temos comentários sobre dois livros em torno de Lima Barreto. A biografia do autor, Lima Barreto: triste visionário, assinada por Lilia Moritz Schwarcz, é comentada por Caion Meneguello Natal, que aponta tratar-se de um perfil "em que estão sintomatizados os referenciais de classificação daquele momento, que eram, principalmente, os 
preconceitos de cor, classe e origem social". Na sequência, em texto de Alexandre Juliete Rosa, é abordada a obra Lima Barreto, caminhos de criação: Recordações do escrivão Isaías Caminha, organizada por Carmem Lúcia Negreiros de Figueiredo e Ceila Maria Ferreira. Trata-se, de acordo com Alexandre, da primeira edição crítica do romance de estreia do autor, acompanhada de uma análise fina que contesta e procura desfazer a ideia de "escritor desleixado", comumente associada a Barreto. O último livro a ser resenhado é Muito d'alma: cartas de Paulo Barreto (João do Rio) a João de Barros - I909-I92I, organizado por Claudia Poncioni e Virginia Camilotti. O pesquisador Rodrigo Jorge Ribeiro Neves avalia a troca de missivas entre os dois escritores e jornalistas e constata tratar-se de um rico documento em torno do diálogo entre Brasil e Portugal no início do século XX.

Já a seção Documentação deste número está integralmente dedicada ao crítico teatral Sábato Magaldi, concebido como um pequeno dossiê. O perfil inicial, "Sábato Magaldi vivo”, assinado por João Roberto Faria (Faculdade de Filosofia, Letras e Ciências Humanas - FFLCH/USP) e Marcos Antonio de Moraes (IEB/USP), apresenta uma breve retrospectiva da vida e atuação desse intelectual. Em seguida, em "Sábato por Edla”, a escritora Edla Van Steen - que foi casada com Sábato e muito contribuiu para a divulgação de sua obra - responde a diversas perguntas sobre a trajetória do crítico. Por fim, mas não menos importante, no texto “Mário, Sábato", de Marcos Antonio de Moraes, temos a transcrição de uma carta inédita que Mário de Andrade destinou a Sábato em I944 - documento esse que Edla pretende doar ao IEB.

Como se vê, o cardápio deste número apresenta assuntos variados, cobrindo em grande parte diferentes aspectos dos "estudos brasileiros", expressão cuja complexidade não deve ser subestimada. Mas não apenas. Ao lado de artigos que problematizam objetos já tradicionalmente aceitos como integrantes desse "campo" - tais como a cultura caipira, a produção dos escritores modernistas, as produções culturais de ou sobre negros, as práticas indígenas etc. - trazemos para a revista textos que abordam temas não associados necessariamente à "brasilidade", tais como os textos produzidos por pesquisadoras francesas. Isso se deve ao fato de que nos posicionamos por uma visão aberta de cultura, na qual a ideia de fronteiras torna-se cada vez mais insipiente. Ao nosso ver, é fundamental cultivar também a contribuição teórico-metodológica de objetos culturais que não se encerram nas limitações (geográficas, políticas, linguísticas, culturais etc.) do que se compreende como Brasil. Textos dessa natureza estimulam reflexões comparativas, cada vez mais necessárias, e nos levam a pensar como são apropriados os objetos culturais, intelectuais e materiais que circulam na sociedade moderna. Ao abrir os olhos para o mundo, saberemos observar melhor o nosso país e as nossas coisas. Afinal, estamos em pleno século XXI.

\section{Fernando Paixão, Ana Paula Cavalcanti Simioni, Flávia Camargo Toni Editores $^{\mathrm{I}}$}

DOI: http://dx.doi.org/Io.II6o6/issn.23I6-90IX.voi68p7-Io

I Docentes e pesquisadores do Instituto de Estudos Brasileiros - USP. 